\title{
The Dublin SURGE Project: geochemical baseline for heavy metals in topsoils and spatial correlation with historical industry in Dublin, Ireland
}

\author{
M. M. Glennon $\cdot$ P. Harris $\cdot$ R. T. Ottesen • \\ R. P. Scanlon · P. J. O'Connor
}

Received: 31 October 2012/Accepted: 17 July 2013/Published online: 30 August 2013

(C) Springer Science+Business Media Dordrecht 2013

\begin{abstract}
The Dublin SURGE (Soil Urban Geochemistry) Project is Dublin's first baseline survey of heavy metals and persistent organic pollutants in topsoils and is part of a Europe-wide initiative to map urban geochemical baselines in ten cities. 1,058 samples were collected as part of a stratified random sampling programme in the greater Dublin area to give an overview of baseline conditions in the city. Samples were analysed for 31 inorganic elements including heavy metals. Analysis of results indicates that the concentrations of lead, copper, zinc and mercury are strongly influenced by human activities, with elevated concentrations in the city docklands, inner city and heavy industry areas. Sources of heavy metals in these areas may include historical industry,
\end{abstract}

P. J. O'Connor was formerly with the Geological Survey of Ireland, Dublin, Ireland (retired).

M. M. Glennon $(\bowtie) \cdot$ R. P. Scanlon

Geological Survey of Ireland, Dublin, Ireland

e-mail: mairead.glennon@gsi.ie

P. Harris

National Centre for Geocomputation, National University of Ireland, Maynooth, Ireland

R. T. Ottesen

Norges Geologiske Undersøkelse (Norwegian Geological Survey), Trondheim, Norway

P. J. O'Connor

Dublin, Ireland coal burning, re-use of contaminated soil, modern traffic and leaded paint and petrol. Concentrations of other inorganic elements in topsoil show patterns which are strongly related to regional bedrock parent material. The spatial distributions of heavy metals, in particular $\mathrm{Pb}$ and $\mathrm{As}$, are explored in detail with respect to regional geology and the influence of historical industry on soil quality. Exploratory data, geostatistical and correlation analyses suggest that the concentrations of heavy metals tend to increase as the intensity of historical industrial activity increases. In particular, drinks production, power generation, oil/ gas/coal, metals and textile historical industries appear to be the contamination source for several heavy metals. The data provide a geochemical baseline relevant to the protection of human health, compliance with environmental legislation, land use planning and urban regeneration.

Keywords Urban geochemistry · Heavy metals - Soil pollution · Historical industry · Human health

\section{Introduction}

Soil is an essential component of terrestrial ecosystems which fulfils numerous important functions, such as acting as a growing medium for plants, filtering and storing water, supporting biodiversity, nutrient cycling and acting as a foundation for built structures (Bullock 
and Gregory 1991). In urban areas, human activities over time have altered soil's natural chemical and physical properties through construction, industry, domestic fossil fuel burning, transport emissions and waste dumping (O'Connor 2005; Biasioli et al. 2006). As a consequence of this interaction, concentrations of contaminants in urban soils may reach levels that give rise to concern for human health, especially for children (Mielke et al. 1999; Biasioli et al. 2006).

An increasing proportion of people live in cities worldwide, with $62 \%$ of the Irish population now living in urban areas (CSO 2012). Therefore, it has become increasingly important to understand, monitor, remediate and prevent contamination in urban amenity soils. Most cities worldwide have wellestablished monitoring systems for air and water, while soils have received comparatively little attention in Ireland. Over a long period of time, soil is generally the main receptor for much of the urban contamination, both from diffuse and point sources (Johnson and Demetriades 2011; Mielke et al. 1999). Topsoil tends to have higher concentrations of metals derived from human activity than other soil horizons due to atmospheric deposition and abundant organic matter (Alloway 1990). Urban inhabitants are readily in contact with topsoil in gardens, playgrounds and sports fields, and it is used as the growing medium for crop cultivation in domestic urban gardens. Potential human exposure pathways to contaminants in soil include ingestion of home grown crops, dermal contact and inhalation of soil dust (Jeffries and Martin 2009).

Until the completion of this study, no systematic baseline geochemical information existed for Irish urban environments. A geochemical baseline is the concentration at a specific point in time of a chemical element, species or compound in a sample of geological material (FOREGS definition cited in Johnson and Ander 2008). Understanding the present environmental conditions is important in responding to soil contamination events and for assisting in the establishment of appropriate health criteria for soil (Johnson and Ander 2008). Ireland does not yet have dedicated contaminated land guidance derived exclusively for the Irish environment. For contaminations like $\mathrm{Pb}$, there is no consensus worldwide on the protective threshold for human health in soil (Abel et al. 2010), and therefore, it is important to understand local conditions in assessing risks to human health from soil contaminants.
The Geological Surveys of Europe (EuroGeoSurveys) initiated an urban soils project, known as the URGE (URban GEochemistry) project, in order to highlight the importance of urban soils to environmental health in European cities. Under this initiative, ten European cities are to be mapped using harmonised sampling and analytical procedures in order to ensure comparability and to assist international understanding of anthropogenic and geogenic influences on soil geochemistry in diverse urban environments. The Geological Survey of Ireland, in partnership with the Geological Survey of Norway (NGU), undertook systematic geochemical mapping of persistent organic pollutants and heavy metals in topsoils in the greater Dublin urban area, known as the Dublin SURGE (Soil Urban Geochemistry) Project. The aim of the survey was to establish Ireland's first urban geochemical baseline, with a view to assessing the spatial distribution of natural and man-made soil constituents and developing geochemical maps that can be used for land use planning, environmental management and health risk assessment. This paper summarises the inorganic elements survey and results.

The geochemistry of rural Irish topsoil has been mapped as part of the Soil Geochemical Atlas of Ireland (Fay et al. 2007) and the FOREGS Geochemical Atlas of Europe (Salminen 2005). Both found that baseline topsoil concentrations correlated closely with underlying regional geology, with some localised elevated concentrations of elements identified in relation to urban areas, mining and intensive agricultural activities. In order to directly link the Dublin urban baseline with the existing rural baseline, eight National Soil Database (NSDB) archive samples, previously reported in the Soil Geochemical Atlas of Ireland (Fay et al. 2007), were reanalysed along with the Dublin SURGE samples. This approach allowed the direct comparison of the SURGE results with the existing rural baseline and assisted with the identification of the anthropogenic contribution to urban soil geochemical concentrations.

\section{Materials and methods}

Study area

\section{Geological setting}

Dublin is Ireland's capital and largest city, with a population of 1.1 million people (CSO 2012). The 
study concerns the greater Dublin area including Dublin's satellite towns, covering an area of just over $500 \mathrm{~km}^{2}$ (Fig. 1). Dublin city is underlain by the Dublin Basin, a geological region composed of poorly differentiated Lower Carboniferous basinal limestones and shale (McConnell 1994). The city is bounded in the south by the upland Leinster granite region of the Wicklow mountains. The Leinster granites are surrounded by a metamorphosed region of fine-grained metasediments (schists, shales and siltstones) (McConnell 1994). There is a variety of natural mineral occurrences in the region including lithium, tungsten and significant lead and zinc-bearing veins of galena, sphalerite and pyrite (McArdle et al. 1989).

In the greater Dublin area, there are extensive glacial sediments overlying bedrock, consisting of widespread boulder clay or till of varying thicknesses (up to $40 \mathrm{~m}$ ) and areas of thick alluvial material along the River Liffey (McConnell 1994; Farrell and Wall 1990). Subsoil composition is dominated by the parent lithology, with tills mainly derived from limestone in central and northern Dublin city and tills derived from granites in the south. Natural topsoils in the greater Dublin area are classed as grey brown podzolics (calcareous soils formed from limestone parent material) (Fay et al. 2007). However, much of the soil in Dublin's inner city has been subject to human alteration through land reclamation from the sea, uncontrolled landfilling of quarries and refuse dumping, most notably in the low-lying docklands area (Farrell and Wall 1990). Between 3 and 6 m of fill was required to bring Dublin's intertidal zone above the high tide level to the region of $3.4 \mathrm{~m}$ O.D. (Farrell and Wall 1990). Made ground in Dublin is characterised by a high degree of variation in natural and man-made constituents, often including plastic, brick, glass, ceramics, construction rubble and historical industrial waste such as ash, clinker and metals.

\section{Industrial and settlement history}

Dublin's industrial and settlement history are important considerations in the interpretation of the modern soil geochemical baseline. Dublin was founded in the ninth century on the south bank of the River Liffey, and a process of land reclamation over the ensuing centuries saw the building of quay walls and the infilling of marshy land to provide for settlement. Industrialisation began in Dublin in the mid- to late-nineteenth century, with activities focussed on the docklands area for shipping, exports and the distribution of imports (DDDA 2010). The docklands were a major distribution and stockpiling centre for imported coal, and industries relying on coal grew around the docklands. Dublin was not heavily industrialised to the same extent as the industrial cities of England (National Archives 2010), and it became Ireland's capital and main centre for government, commerce and employment.

Coal was significant in Dublin's industrial past as the dominant fuel in domestic fires, industrial furnaces, steam engines and power generation facilities from the late nineteenth century to the mid-twentieth century (Carrig 2011). During the 1980s, domestic coal burning reached a peak in Dublin city, causing severe black smoke and smog pollution during that decade (Clancy 2010). A ban prohibiting the sale, marketing and distribution of bituminous coal came into effect in 1990, after which a $71 \%$ decrease in black smoke particulates was observed (Clancy 2010). Emissions and by-products of coal combustion (ash, clinker and tar) are associated with heavy metals and organic compound contamination (Fuge 2005).

Following the eradication of bituminous coal burning in Dublin, road traffic emissions are now the biggest threat to air quality (EPA 2009). Unleaded petrol was introduced in the 1980s in Ireland and the phasing out of leaded petrol was completed in 2000. It is estimated that $75 \%$ of environmental $\mathrm{Pb}$ is sourced from vehicle exhausts (Fuge 2005). During the phasing-out period, ambient $\mathrm{Pb}$ levels dramatically decreased and have remained low since 2000 (EPA 2009).

Sample collection

The aim of the field campaign was to sample soil in locations where members of the public may come into contact with the soil. A stratified random sampling strategy was adopted to give an unbiased overview of soil quality in the city. The sampling did not target or avoid sites of known or suspected contamination. Sample locations were generated randomly using ArcGIS software within a $1 \mathrm{~km}^{2}$ grid and were modified to coincide with local authority-owned land. A total of 1,058 samples were collected over a 12-day period in October and November 2009 by four teams of NGU samplers.

From each location, a point sample of 300-500 $\mathrm{g}$ of surface soil was collected from a depth of $0-10 \mathrm{~cm}$ 


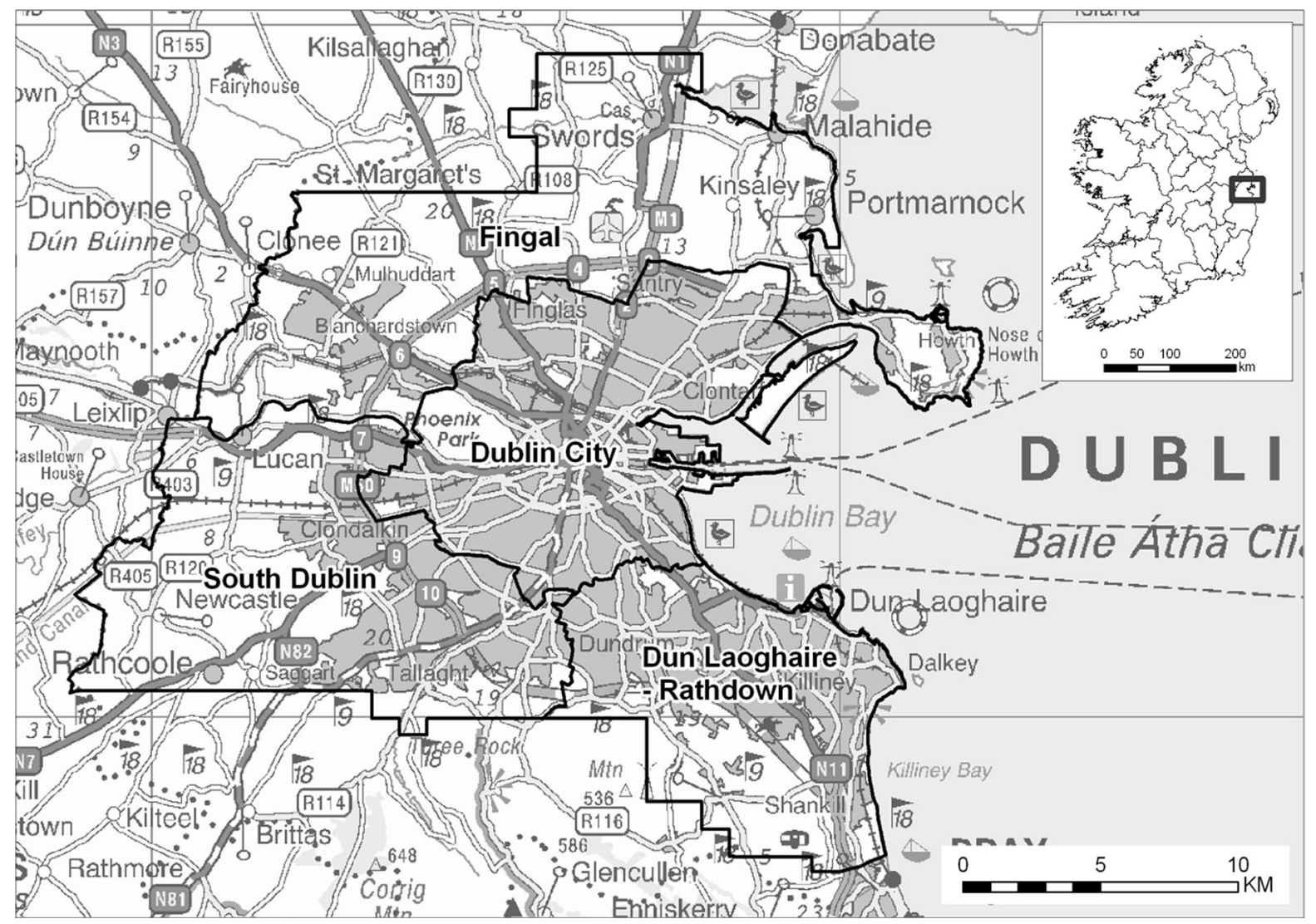

Fig. 1 The greater Dublin area with local authority areas indicated. Basemap copyright $@$ Ordnance Survey Ireland/Government of Ireland. OSI Licence No. 0047209

with a clean metal garden trowel or spade and stored in inert Rilsan ${ }^{\circledR}$ plastic bags. If grass was present at the sampling location, a knife was used to cut away grass. At each site, a photograph was taken and a Global Positioning System was used to determine the sampling location coordinates, with $\pm 5 \mathrm{~m}$ accuracy for $95 \%$ of samples.

\section{Laboratory analysis}

Samples were prepared and analysed for 31 inorganic elements at NGU laboratory, Trondheim. The samples were air-dried at $<30{ }^{\circ} \mathrm{C} /$ ambient temperature and sieved through a $2 \mathrm{~mm}$ nylon sieve. The $<2 \mathrm{~mm}$ sieved fractions were digested by acid extraction in a microwave system, UltraClave IV, Milestone, according to a modification of USEPA method 3051 (USEPA 2007). One gram of sample material was weighed into a PTFE vessel before $15 \mathrm{ml} 7 \mathrm{M} \mathrm{HNO}_{3}$ was added. The mixture was carefully stirred on a Vortex Genie shaker to ensure that the sample was completely wetted by the acid. The samples were then heated under nitrogen pressure up to $250{ }^{\circ} \mathrm{C}$. The acid extractions from the samples were filtered using $90 \mathrm{~mm}$ diameter Whatman folded filters to remove residues that were not digested by the acid. Thirty elements were determined with an inductively coupled plasma-atomic emission spectrometry (ICP-AES) instrument PerkinElmer Optima 4300 Dual View. Mercury was determined with a cold-vapour atomic absorption spectrometer (CV-AAS) instrument CETAC M-6000A Hg Analyzer. Loss on Ignition was determined by heating the samples at $480{ }^{\circ} \mathrm{C}$ for $20 \mathrm{~h}$.

Quality assurance

\section{Reproducibility}

Field teams collected duplicate samples from 30 of the primary sampling locations throughout the area. The 
duplicates were sampled concurrently with the primary samples, by the same team, but from a separate pit typically 1-10 $\mathrm{m}$ apart from the primary location. Scatter plots comparing the primary and duplicate analytical results indicated acceptable reproducibility for all elements. No plots are made for $\mathrm{Si}$, as the procedures are not certified for $\mathrm{HNO}_{3}$-extraction of $\mathrm{Si}$ in geological material.

\section{Analytical precision and accuracy}

To monitor for analytical precision throughout the analytical process, five in-house NGU natural material standards were introduced to the sample batch prior to extraction. The standards consisted of two marine sediments, one of which is heavily contaminated by $\mathrm{As}, \mathrm{Cu}, \mathrm{Pb}$ and $\mathrm{Zn}$, and three different splits of an overbank sediment sample with low to moderate concentrations of the elements of interest for this study. Analytical results for each standard were plotted in analytical sequence. The plots show no significant shifts in the values reported for each standard.

Analytical accuracy was assessed through the insertion and analysis of three certified reference materials (CRMs), MESS-3 (National Research Council Canada), NIST2709 (National Institute of Standards and Technology) and SO2 (Canadian Certified Reference Materials Project). Results with relative standard deviation (RSD) from certified values higher than $10 \%$ were considered unsatisfactory. Results for $\mathrm{Ti}, \mathrm{Cd}$ and $\mathrm{Zr}$ were slightly higher than the certified values, but the results are accepted since the $\mathrm{HNO}_{3}$ extraction of the CRM yields very low values compared to the detection limit. An unacceptably high RSD for Mo led to a high level of uncertainty in the accuracy of the Mo determination, even though field duplicates show acceptable reproducibility. Molybdenum was therefore left out of further processing.

Geochemical baseline

\section{National Soils Database samples}

Eight rural NSDB samples were retested in the SURGE analytical batches and compared with the results reported in the Soil Geochemical Atlas of Ireland. The SURGE project used a less aggressive (nitric acid) extraction compared to the near-total hydrofluoric acid extraction used in the Soil Geochemical Atlas of Ireland study, resulting in lower reported element concentrations. Scatter plots of concentrations obtained in the original and retested NSDB samples for eight elements (As, $\mathrm{Cd}, \mathrm{Cr}, \mathrm{Cu}, \mathrm{Hg}$, $\mathrm{Ni}, \mathrm{Pb}$ and $\mathrm{Zn}$ ) show that the different extractions give consistent results. The $r^{2}$ values are $>0.9$ in most cases indicating excellent correlation between the two surveys. The re-tested NSDB samples results were used to assist the derivation of a baseline from the urban soil concentrations. For other inorganic elements, the strength of the relationship between elements measured in original and retested NSDB samples varied due to the difference in extraction capabilities of the two acid digestions on resistant silicate materials present in the samples.

\section{Exploratory data analysis}

A selection of exploratory data analysis (EDA) tools is used to illustrate the nature of the inorganic elements in soil-basic summary statistics (mean and standard deviation), robust (outlier resistant) summary statistics [median and inter-quartile range (IQR)], histograms and cumulative normal percentage probability (CPP) plots. Analogous to the (non-robust) mean and standard deviation, the median and the IQR provide robust measures of central tendency and data spread, respectively. CPP plots are superimposed on each element's histogram, in order to fully visualise the distribution of each data set. Deviations from a normal distribution, which occur commonly in environmental data (Reimann et al. 2008), are easily identified with these graphics. Conditional boxplots are also used to visualise how the concentrations of soil chemicals change with different city zones, land uses, soil types and bedrock types. In the preparation for such analysis (and subsequent analyses described below), concentrations reported below the lower limit of detection are assigned values of half the detection limit. In addition, one sample is removed from the soils data set since it is found to be co-located with another. Thus, a reduced data set of 1,057 observations is used in all analyses.

\section{Geostatistical analysis}

A preliminary study into the spatial process (or distribution) of each inorganic element is undertaken via a geostatistical methodology (e.g. Chilès and 
Delfiner 1999). Here we assume a simple, continuous spatial process for each element, whereas it is much more likely that each process is discontinuous, operating at different spatial scales. Such complex urban processes require a substantive piece of research that is beyond the scope of this study, but should be integral to any analysis conducted at a later stage. That said, assuming and modelling a continuous process should still provide valuable insights into the behaviour of each inorganic element at a broad spatial scale. Furthermore, only univariate models are considered. Extensions to a multivariate form, where spatial variation in each element is additionally informed by useful contextual data (e.g. land use, historical industry data, etc.), will be presented elsewhere. Thus, the geostatistical outputs of this study could be viewed as benchmark results, where future work would aim to improve on them. Future work may also benefit some additional but targeted sampling to aid model calibrations.

Using the Empirical Maximum Likelihood Kriging (EMLK) method of Pardo-Igúzquiza and Dowd (2005a), prediction and prediction uncertainty surfaces (or maps) are found for each element, so that spatial distributions of elements in soil are determined. EMLK is a sophisticated kriging method where more efficient results are obtained by solving the prediction problem in the Gaussian domain via a normal scores transform of the sample data (a logarithmic or similar transform does not completely ensure normality, whereas a normal scores transform does). Furthermore, a Bayesian component in EMLK ensures conditionally unbiased results where a posterior predictive distribution is found at all target locations. Here the mean of the posterior distribution is taken as the EMLK prediction, and the variance of the posterior distribution can be used to assess the uncertainty of the EMLK prediction. Details and applications of the EMLK algorithm can be found in Pardo-Igúzquiza and Dowd (2005a, b) and Pardo-Igúzquiza and Chica-Olmo (2005) where a FORTRAN program (EMLK2D.F95) is available that provides EMLK outputs on a grid.

EMLK is chosen to model the study data, in so much that it is (i) advocated for non-normal data sets, including those with observations below the lower limit of detection; (ii) able (via its Bayesian construction) to provide a more realistic approach to prediction uncertainty than that found in many basic algorithms, such as ordinary kriging (for discussions, see Journel
1986; Heuvelink and Pebesma 2002); and (iii) opensource. EMLK also requires much less work than indicator kriging which is a common choice for modelling processes similar to that of this study, with similar objectives (see Goovaerts 2009).

To calibrate EMLK models, variogram parameters are statistically and directly estimated using a restricted maximum likelihood (REML) approach (e.g. Ribeiro and Diggle 2001) where only (isotropic) spherical, exponential or Gaussian variogram models are specified. Starting parameters for the REML fits are those estimated from a weighted least squares fit to the corresponding empirical variogram. This procedure allows some considered input from the analyst in the variogram fitting procedure. Variography is conducted on the normal scores data sets which should also reduce any adverse effects due to outlying observations. All EMLK fits are specified with a constant trend term with neighbourhoods taken as the nearest 25 observations.

Observe that we only specify isotropic variograms. Some elements, however, suggested anisotropic structures, where spatial continuity is stronger in some directions than others. Commonly, such behaviour only occurred at a fairly large spatial scale, whereas at local, smaller spatial scales, spatial continuity was isotropic. This entails that in choosing a relatively local EMLK neighbourhood of 25 observations, the pragmatic use of isotropic variograms is well-judged, yielding results little different to those that would be found if anisotropic variograms had been specified (for those elements that indicated the need).

\section{Historical survey}

\section{Methodology}

To gain a greater understanding of how past industrial activity may have affected soil quality in Dublin, the GSI commissioned historians to complete a survey of Dublin's industrial history. The survey recorded the location, nature and operating periods of potentially polluting industries by identifying annotated industries on nineteenth and twentieth century Ordnance Survey maps (at $6 \mathrm{inch} / 1: 1,056$ and $25 \mathrm{inch} / 1: 2,500$ scales). Over 2,000 sites were identified on the historical maps and from existing industrial heritage surveys commissioned by Dublin City and Dun Laoghaire-Rathdown local authorities. The data were 
classified into eleven categories of industry and spatially referenced in an ArcGIS shapefile.

\section{Spatial kernel density estimation and correlation analysis}

In order to provide quantifiable relationships between the 'point process' historical industry data sets and the 'continuous process' soil geochemistry data sets, spatial kernel density estimation (SKDE) is applied (e.g. Diggle 1990). Here SKDE models are calibrated using the historical industry coordinate data as input data together with the inorganic geochemistry coordinate data as output data. This exploratory procedure assigns a set of density estimates (one for each industry category) to each geochemistry site, where the density estimates reflect the intensity of bygone industrial activity nearby. In turn, this enables correlation coefficients between the density estimates and each inorganic element to be found. A significant positive correlation between a given inorganic element and a given density estimate for a particular industry type can be interpreted as a potential historical source of soil contamination. The same SKDE models are also calibrated for gridded surface outputs, so that the intensity of a given historical industrial activity can be visualised.

\section{Results and discussion}

\section{Geochemical baseline}

Heavy metals which are closely associated with human activity and known to pose risks to human health (the "anthropogenic" metals As, Be, Cd, Co, $\mathrm{Cr}, \mathrm{Cu}, \mathrm{Hg}, \mathrm{Ni}, \mathrm{Pb}, \mathrm{V}$ and $\mathrm{Zn}$ ) were characterised in relation to their occurrence and spatial distribution in Dublin. Basic and robust summary statistics for these eleven elements are presented in Table 1 along with the method detection limit (MDL) and the proportion of samples below this limit. Results which were reported as below the MDL were replaced with a value of one half of the MDL for the purposes of statistical analysis. For many metals, there is little difference in their mean and median values indicating weak evidence of outlying or anomalous observations. The exceptions are $\mathrm{Cu}, \mathrm{Hg}, \mathrm{Pb}$ and $\mathrm{Zn}$, all of which have a few outlying but valid, high-valued observations, believed to be associated with anthropogenic contamination in the inner city. Results for these metals, along with As, are presented in detail and subjected to geostatistical analysis.

Lead

Particular attention is given to $\mathrm{Pb}$ as urban soil $\mathrm{Pb}$ is well understood to be a significant source of human exposure to $\mathrm{Pb}$, especially amongst children, who are more susceptible to lead-related adverse health effects (Mielke et al. 1999). Lead has been used in batteries, ammunition, water supply pipes, roofing materials; as an additive to paint, petrol and pesticides; and in the manufacture of glass, pottery and ceramics (Davies 1990; ATSDR 2007a). Combustion processes such as the leaded petrol combustion, smelting and $\mathrm{Pb}$ metalworks can emit $\mathrm{Pb}$ particles to the atmosphere which in turn can be deposited in soils. Lead can be deposited in soils due to weathering of building materials and dumping of lead-containing materials. Key graphics for the (non-spatial) exploratory and (spatial) geostatistical analyses for $\mathrm{Pb}$ are presented in Figs. 2, 3 .

The $\mathrm{Pb}$ data displayed a positively skewed distribution with a long disjointed tail. A (natural) log transformed data set reduces skew but still provides a far from normal distribution (see Fig. 2a). On examination of the CPP plot in Fig. 2a, there is no clear evidence of multiple populations (commonly depicted by clear breaks or jumps in the CPP plot). This aspect requires further investigation as it would be expected for $\mathrm{Pb}$ to relate to geogenic background, natural geogenic anomalies and an anthropogenic component. It is likely such populations are being masked by each other. Furthermore, the study sampling density may not be sufficient to observe such behaviour. Separation of the $\mathrm{Pb}$ baseline into anthropogenic and geogenic components is complex for Dublin as there are known $\mathrm{Pb}$ mineral occurrences which have been worked economically in the area.

REML and empirical variography for the $\mathrm{Pb}$ data are presented in Fig. 2b. For the REML model, the correlation range parameter $a$ is estimated at $4,920 \mathrm{~m}$, while the parameters $c_{0}$ and $c_{1}$ are estimated at 0.35 and 0.59 , respectively. The partial sills $c_{0}$ and $c_{1}$ reflect small- and large-scale spatial variation, respectively ( $c_{0}$ is where the variogram appears to intercept the $y$ axis and is known as the nugget variance). Strong spatial dependence exists when the correlation range is 
Table 1 Basic statistics for key anthropogenic inorganic elements

\begin{tabular}{|c|c|c|c|c|c|c|c|c|c|}
\hline & $\begin{array}{l}\text { MDL } \\
\left(\mathrm{mg} \mathrm{kg}^{-1}\right)\end{array}$ & No. $<\mathrm{MDL}$ & $\%<\mathrm{MDL}$ & $\begin{array}{l}\operatorname{Min} \\
\left(\mathrm{mg} \mathrm{kg}^{-1}\right)\end{array}$ & $\begin{array}{l}\operatorname{Max} \\
\left(\mathrm{mg} \mathrm{kg}^{-1}\right)\end{array}$ & $\begin{array}{l}\text { Mean } \\
\left(\mathrm{mg} \mathrm{kg}^{-1}\right)\end{array}$ & $\begin{array}{l}\text { Median } \\
\left(\mathrm{mg} \mathrm{kg}^{-1}\right)\end{array}$ & $\begin{array}{l}\text { SD } \\
\left(\mathrm{mg} \mathrm{kg}^{-1}\right)\end{array}$ & $\begin{array}{l}\text { IQR } \\
\left(\mathrm{mg} \mathrm{kg}^{-1}\right)\end{array}$ \\
\hline As & 3 & 4 & 0.4 & $<3$ & 402 & 15.5 & 13.4 & 15.2 & 5.7 \\
\hline $\mathrm{Be}$ & 0.15 & 0 & 0 & 0.16 & 11.3 & 1.42 & 1.35 & 0.54 & 0.43 \\
\hline $\mathrm{Cd}$ & 0.15 & 3 & 0.3 & $<0.15$ & 10.5 & 1.77 & 1.74 & 0.66 & 0.63 \\
\hline Co & 0.15 & 0 & 0 & 0.39 & 24.8 & 9.8 & 9.58 & 2.54 & 2.79 \\
\hline $\mathrm{Cr}$ & 0.3 & 0 & 0 & 4.24 & 262 & 44.2 & 44.3 & 11.8 & 9.3 \\
\hline $\mathrm{Cu}$ & 1.5 & 1 & 0.1 & $<1.5$ & 6,480 & 50.7 & 35 & 203 & 19.7 \\
\hline $\mathrm{Hg}$ & 0.0075 & 0 & 0 & 0.0135 & 23.9 & 0.339 & 0.206 & 0.825 & 0.232 \\
\hline $\mathrm{Ni}$ & 1.5 & 0 & 0 & 5.5 & 145 & 40.7 & 41 & 10.9 & 11.9 \\
\hline $\mathrm{Pb}$ & 3 & 1 & 0.1 & $<3$ & 3,120 & 123 & 73.7 & 192 & 81 \\
\hline $\mathrm{V}$ & 1.5 & 0 & 0 & 10.8 & 114 & 70.4 & 72.1 & 14.7 & 17.7 \\
\hline $\mathrm{Zn}$ & 3 & 0 & 0 & 18 & 8,390 & 248 & 172 & 373 & 92 \\
\hline
\end{tabular}

$M D L$ Method detection limit; $S D$ Standard deviation; IQR Inter-quartile range

relatively long coupled with a high relative structural variation-defined as $\mathrm{RSV}=\left(c_{1} /\left(c_{1}+c_{0}\right)\right) \times$ $100 \%$ (Schabenberger and Gotway 2005). For Pb, spatial dependence is viewed as moderate to weak, since RSV is low at $37.2 \%$. This RSV value stems from a high nugget variance, which is expected with heavy metals in urban environments, since measurements can vary strongly from high to low over the shortest sample distances. This may also suggest that the sample scale is too broad, where sampling on a finer scale may lower this variance. This variance may also in part reflect (laboratory) measurement error.

For comparison with the REML fit, the empirical variogram is presented, where in this case, the REML model has a different structure to its empirical counterpart. Commonly, the two variogram forms would show a stronger similarity and it may be prudent (for future work) to re-specify the REML fit with a wave model instead of the Gaussian. Retaining the Gaussian model is not considered problematic here, however, as kriging predictions are known to be fairly robust to variogram model misspecification (Stein 1999).

Surfaces stemming from the kriging (EMLK) outputs are presented in Fig. 2c, d, along with the 1,057 study sites. From the prediction surface (Fig. 2c), the highest concentrations of $\mathrm{Pb}$ occur in the oldest inner city parts of Dublin, with levels declining concentrically with distance from the city centre. Other urban soil $\mathrm{Pb}$ studies from around the world have clearly demonstrated a similar pattern (including Abel et al. 2010; Haugland et al. 2008; and studies cited in Davies 1990). According to our chosen scale breaks, the highest $10 \%$ predictions (predominantly in the city centre) can range from just under $200 \mathrm{mg} \mathrm{kg}^{-1}$ up to highs of over $470 \mathrm{mg} \mathrm{kg}^{-1}$. Progressively lower levels are predicted in the inner suburbs and outer suburbs. $\mathrm{Pb}$ predictions in rural areas around the city have concentration levels below $50 \mathrm{mg} \mathrm{kg}^{-1}$, which is consistent with levels observed in the re-tested rural NSDB soils which ranged between 30.8 and $120 \mathrm{mg} \mathrm{kg}^{-1}$. As with any prediction method, smoothing will occur where predictions will have a smaller variance than the actual data (e.g. the highest sampled $\mathrm{Pb}$ value is $3,120 \mathrm{mg} \mathrm{kg}^{-1}$, which is far higher than the highest kriging prediction; conversely, individual observations in outer rural areas are often lower than predicted values). Further, predictions that involve a difficult extrapolation to the edge of the sampled area should be considered unreliable.

It is important that a prediction surface is given with its respective uncertainty surface. Such a surface is presented in Fig. $2 \mathrm{~d}$ for the $\mathrm{Pb}$ predictions, where in this case, uncertainty is shown using $68 \%$ prediction confidence intervals (PCIs) found directly from the posterior predictive distributions that the EMLK method generates. Clearly, even at this moderate level of confidence, there exists a high level of uncertainty in the $\mathrm{Pb}$ predictions. This is entirely expected due to the behaviour of the variogram with its relatively high nugget variance. The spatial pattern in prediction 
A

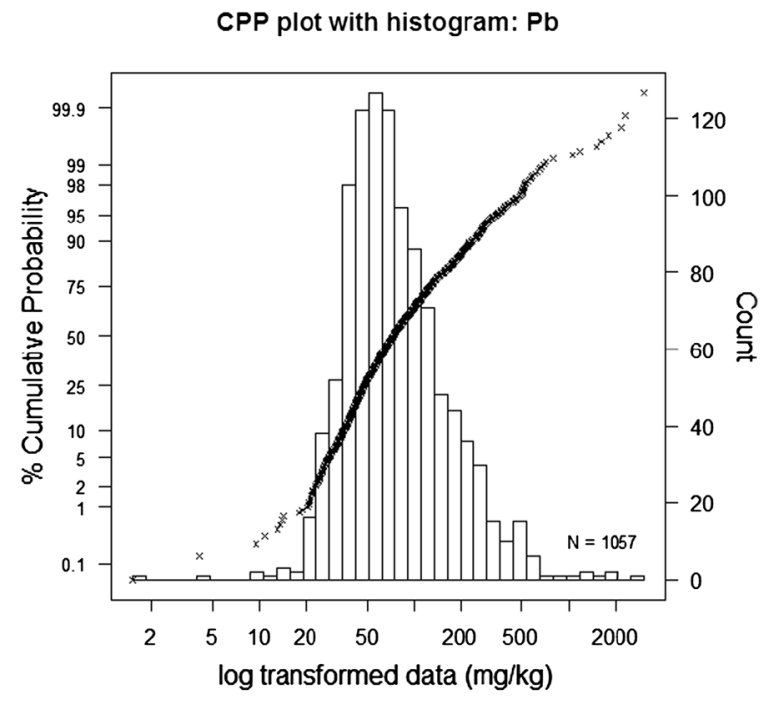

C

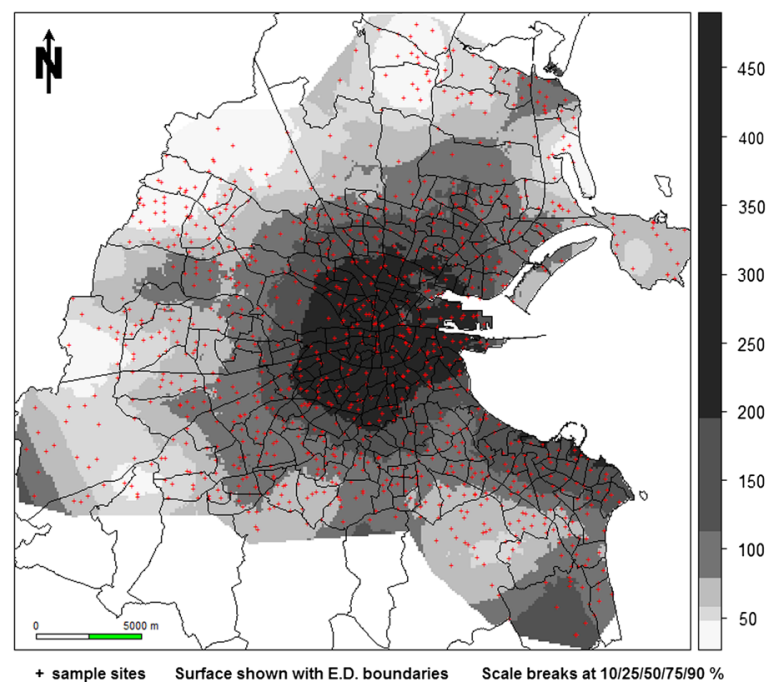

B

Empirical \& REML variograms (Gaussian): Pb

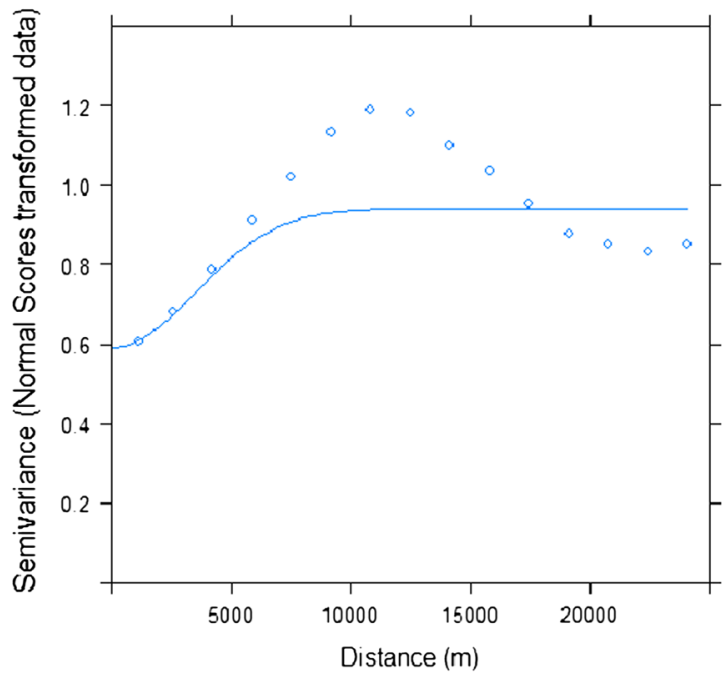

Empirical - points

REML - solid line

D EMLK $68 \% \mathrm{PCl}$-widths surface: $\mathrm{Pb}(\mathrm{mg} / \mathrm{kg})$

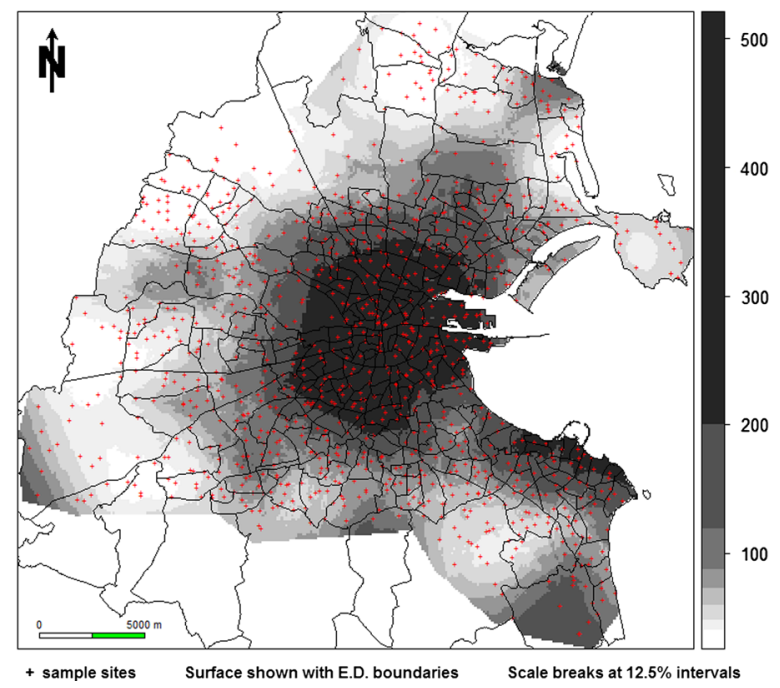

Fig. 2 CPP plot, histogram, variograms and EMLK outputs for Pb. Observe that the REML variogram fit is not a fit to the empirical variogram

uncertainty mimics that of the predictions, where high levels of prediction uncertainty coincide with high predictions and vice versa. This phenomenon is common with environmental data and is referred to as the proportional effect (e.g. Chilès and Delfiner 1999).

The spatial pattern in topsoil $\mathrm{Pb}$ concentrations reflects Dublin's long history of diffuse atmospheric emissions from traffic and coal combustion in inner city homes and industries. UK coals, of which much was historically imported for use in Dublin, are known to contain significant amounts of $\mathrm{Pb}$, and the combustion of such coal releases $\mathrm{Pb}$ and other coal-derived trace elements into the environment as particulate emissions and fly ash (Fuge 2005). Although the use of leaded petrol and lead paint and burning of bituminous coal have been phased out in Ireland, $\mathrm{Pb}$ from these sources is persistent in soils and continuing sources 


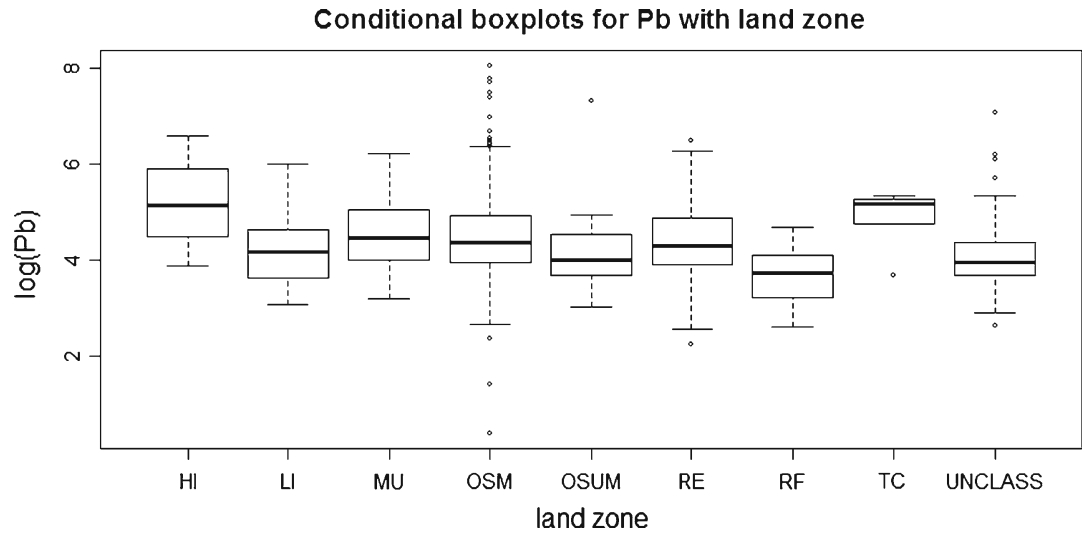

HI - Heavy industry

LI - Light industry

MU - Mixed use

OSM - Open space - managed

OSUM - Open space - un managed

RE - Residential - existing

FF - Residential - future

TC - Town centre

UNCLASS - No zone available

Fig. 3 Conditional boxplots for (natural $\log$ transformed) $\mathrm{Pb}$ with land zone

remain in surfaces painted with lead paint, building materials and waste disposal.

Further analysis of the sampled $\mathrm{Pb}$ concentrations, conditionally sub-setted by subsoil type and by land zone, indicates that $\mathrm{Pb}$ levels are elevated in made ground subsoil and in inner city and heavy industry land zones. Made ground had the highest median level of $\mathrm{Pb}$ of the subsoil categories at $129.5 \mathrm{mg} \mathrm{kg}^{-1}$. It is likely that made ground in the inner city area contains elevated $\mathrm{Pb}$ concentrations due to the historical use of waste materials and fly ash as fill. Conditional boxplots of $\mathrm{Pb}$ by land zone (Fig. 3) also show that town centre and heavy industry zones have the highest concentrations of $\mathrm{Pb}$ compared to other land zones, with median values at 178 and $174 \mathrm{mg} \mathrm{kg}^{-1}$, respectively. There were no clear distinctions between levels of $\mathrm{Pb}$ for different geological units. It can be concluded from the spatial distribution and the conditional analyses of $\mathrm{Pb}$ concentrations that there is a strong influence of anthropogenic inner city activities on soil $\mathrm{Pb}$.

Other anthropogenic metals

Kriging surfaces for three other anthropogenic metals $\mathrm{Cu}, \mathrm{Hg}$ and $\mathrm{Zn}$ are given in Fig. 4, where each displays a similar spatial trend (and its associated uncertainty) to $\mathrm{Pb}$, with the highest concentrations occurring in the historical inner city area and in heavy industry areas. Sample distributions and variograms (not shown) for these metals are also similar in behaviour to that of $\mathrm{Pb}$, where spatial dependence is viewed as moderate to weak in all three cases.
Analyses for As are presented in detail and the key graphics are shown in Figs. 5 and 6. The As data displayed a positively skewed distribution with some prominent outlying observations. An exploratory log transform reduces this skew (see Fig. 5a). Spatial dependence in As (Fig. 5b) is viewed as moderate to weak, since the correlation range is estimated at a relatively short distance of $2,122 \mathrm{~m}$ and the RSV value is low at $41.3 \%$. The spatial distribution of As (Fig. 5c, d) suggests areas of both anthropogenic and geogenic influences on soil As. Enrichments of As occurring in the city centre are likely to be associated with human activity and in rural areas with localised bedrock mineralisation and mining activities.

Anthropogenic activities which are likely to have contributed As to the inner city environment include coal burning, industry and CCA-treated wood (ATSDR 2007b). Coal can contain up to $200 \mathrm{mg} \mathrm{kg}^{-1} \mathrm{As}$ and coal ash can have a wide range of As contents (300-700 mg kg-1), depending on the composition of source coals (Wedepohl 1983). Analysis of the sampled As concentrations, conditionally sub-setted by the type of bedrock (Fig. 6) indicates that high median concentrations of As are observed in the Silurian metasediments of southwest Co. Dublin (at $24.7 \mathrm{mg} \mathrm{kg}^{-1}$ ) and in the Cambrian metasediments and quartzites of Howth Head in north Co. Dublin (at $22.4 \mathrm{mg} \mathrm{kg}^{-1}$ ), compared with other bedrock units in the region. Naturally elevated levels of As are observed in these areas due to arsenopyrite mineralisation and historical mine workings.

The existence of more than one As data population is also indicated by the CPP curve (Fig. 5a) which 

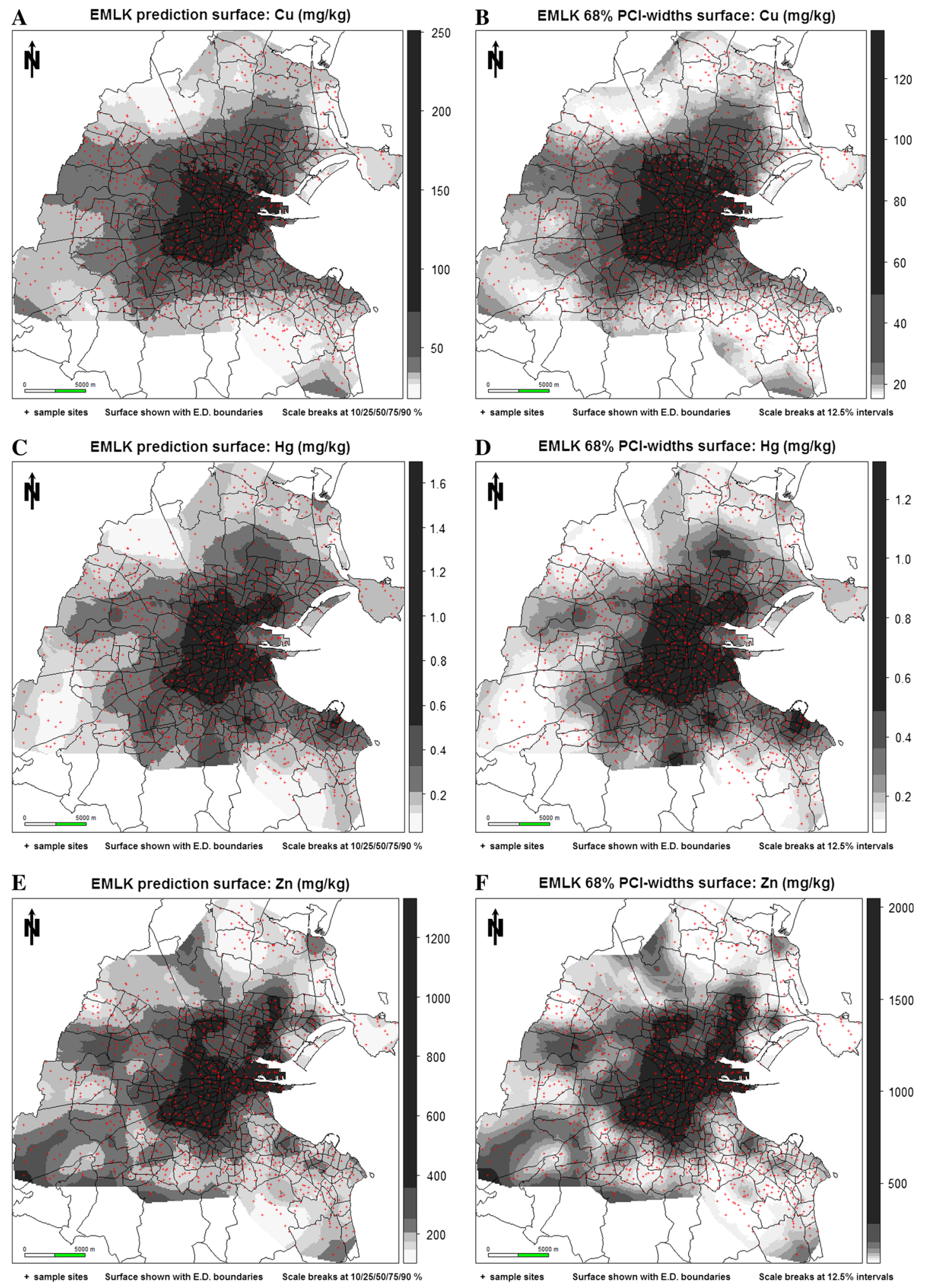

Fig. 4 EMLK outputs for $\mathrm{Cu}, \mathrm{Hg}$ and $\mathrm{Zn}$ 
A

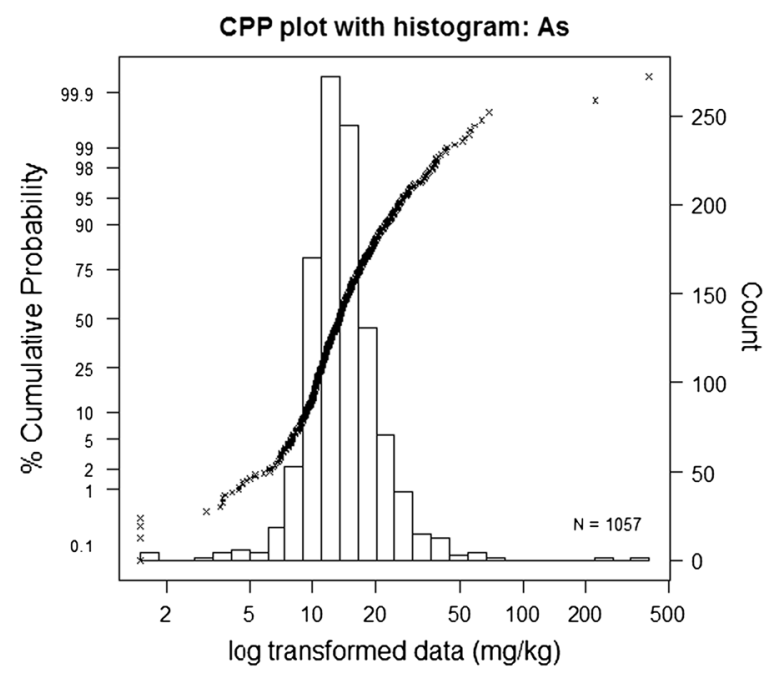

C

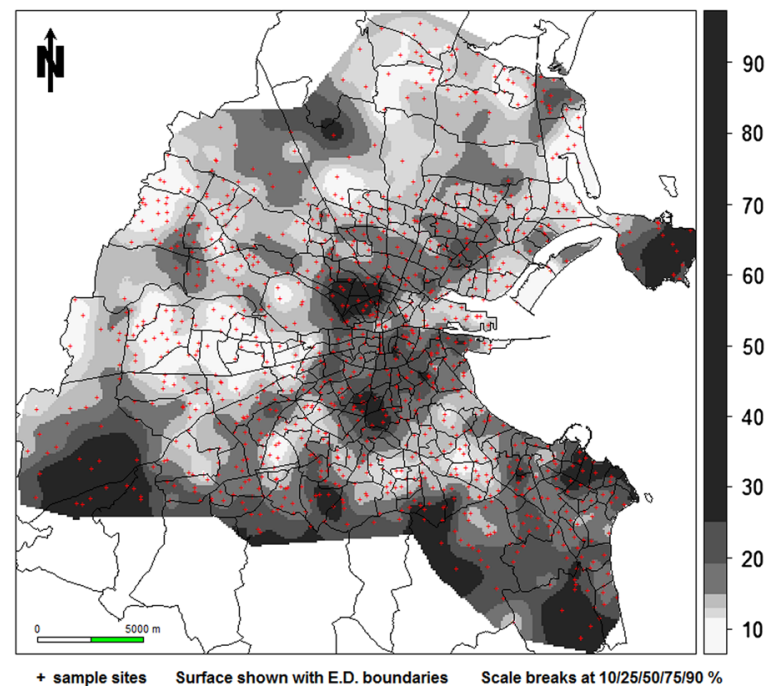

B

Empirical \& REML variograms: As (exponential)

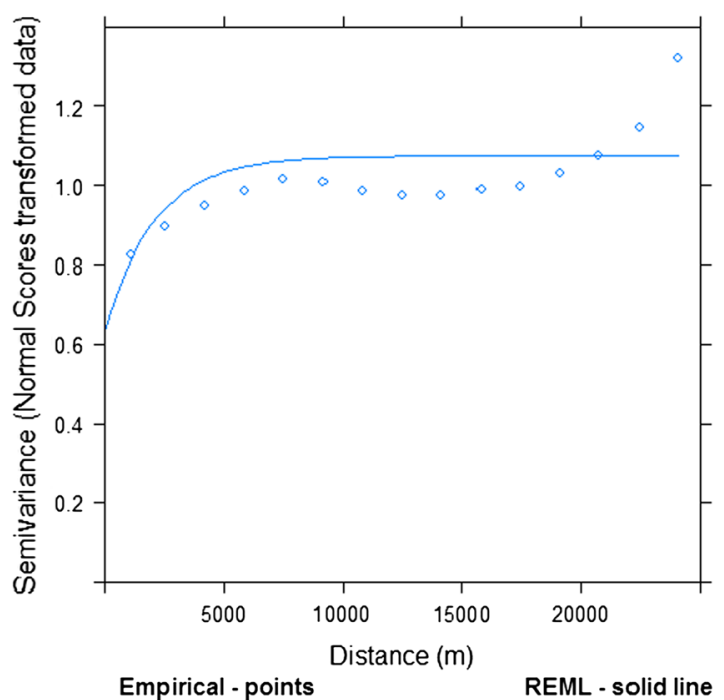

D

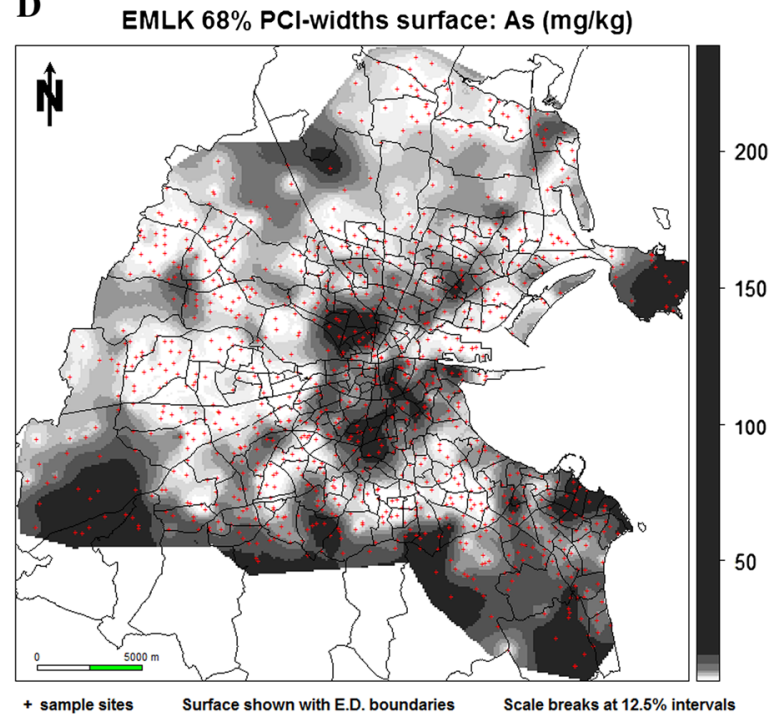

Fig. 5 CPP plot, histogram, variograms and EMLK outputs for As. Observe that the REML variogram fit is not a fit to the empirical variogram

shows a break near the centre of the line at approximately $20 \mathrm{mg} \mathrm{kg}^{-1}$. This is within the rural baseline levels measured in NSDB soils, which range between 10.1 and $27.1 \mathrm{mg} \mathrm{kg}^{-1}$. Levels above the $20 \mathrm{mg} \mathrm{kg}^{-1}$ level are therefore taken to relate to natural As anomalies or anthropogenic contamination.

Arsenic is a confirmed human carcinogen and longterm exposure is associated with cancer of the skin, liver, bladder and lungs (ATSDR 2007b). Of many possible As compounds, inorganic As compounds pose the most risks to human health (ATSDR 2007b). This study determined the total concentration of As, without measuring As species. Bioaccessibility testing of As in Dublin's soil would contribute to a greater understanding of As in soil and groundwater in human health risk assessment, especially where multiple populations of anthropogenic and natural concentrations are suspected. Some forms of naturally occurring 


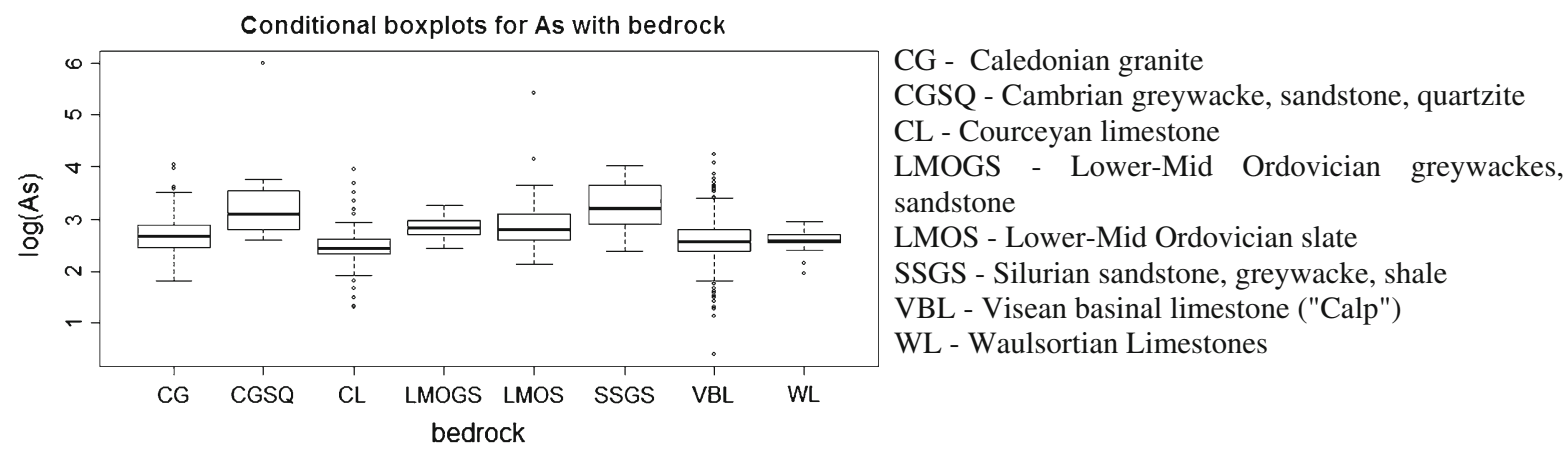

Fig. 6 Conditional boxplots for (natural log transformed) As with bedrock

contaminants may be tightly bound within the soil matrix and pass through the human body without being released and taken up by the body (UK EA 2009).

\section{Geogenic elements}

The spatial distributions of twenty other elements measured as part of this study appear to be strongly determined by regional bedrock. Aluminium, B, Be, $\mathrm{Cd}, \mathrm{Ce}, \mathrm{Co}, \mathrm{Cr}, \mathrm{Fe}, \mathrm{K}, \mathrm{La}, \mathrm{Li}, \mathrm{Mn}, \mathrm{Na}, \mathrm{Sc}, \mathrm{Si}, \mathrm{Y}, \mathrm{V}, \mathrm{Zr}$ are characterised by naturally derived enrichments occurring in the north and northwest of the survey area in the Dublin Basin. This is likely to be a sedimentary signature derived from impure Carboniferous limestones which are variably interbedded with shales and mudstones throughout the Dublin Basin. The alkaline earth metals $\mathrm{Ca}, \mathrm{Sr}$ and $\mathrm{Mg}$ are closely associated in limestones and their similar spatial distributions in the Dublin Basin reflect this. The distributions of $\mathrm{Ba}, \mathrm{P}$ and $\mathrm{Ti}$ are moderately correlated with the anthropogenic metals $\mathrm{Pb}, \mathrm{Hg}, \mathrm{Cu}$ and $\mathrm{Zn}\left(r^{2}<0.77\right)$, indicating a possible anthropogenic influence on these metals.

\section{Historical survey}

The historical survey identified industrial sites across the entire study area, though there are significant concentrations within the inner city area and along the major waterways (Carrig 2011). In total 2,022 historical industry sites were classified into eleven categories: animal products, chemical, drinks, food, oil/gas/ coal, minerals/aggregate, municipal facilities, metals, power generation, pulp/paper and textiles. This data were then reduced by $36 \%$ to 1,289 sites, so as to remove all sites with incomplete information, prior to the SKDE analysis. Pre-processing of the industry data so that all of the 2,022 sites can be used in analyses beyond that of this study is on-going.

For each category, a SKDE is performed using the coordinates of the historical industry data in order to produce density estimates at (i) the coordinates of a grid and (ii) the coordinates of the inorganic geochemistry data. In total, twelve SKDEs are calibrated providing twelve potential covariates to the inorganic elements; where one of the SKDEs uses all of the historical industry sites grouped together. A Gaussian kernel is specified in all SKDEs and the kernel

Table 2 Bandwidths for SKDE data by historical industry type

\begin{tabular}{llllll}
\hline SKDE & Bandwidth $(\mathrm{m})$ & Industry & SKDE & Bandwidth $(\mathrm{m})$ & Industry \\
\hline skde.all & 2,000 & All $(n=1,289)$ & skde.MA & 10,000 & Minerals/aggregate (682) \\
skde.AP & 2,000 & Animal products $(12)$ & skde.MF & 2,000 & Municipal facilities (59) \\
skde.C & 2,000 & Chemical (68) & skde.M & 2,000 & Metals (131) \\
skde.D & 2,000 & Drinks (44) & skde.PG & 5,000 & Power generation (25) \\
skde.F & 2,000 & Food (101) & skde.PP & 2,000 & Pulp/paper (38) \\
skde.OGC & 2,000 & Oil/gas/coal (29) & skde.T & 2,000 & Textiles (100) \\
\hline
\end{tabular}



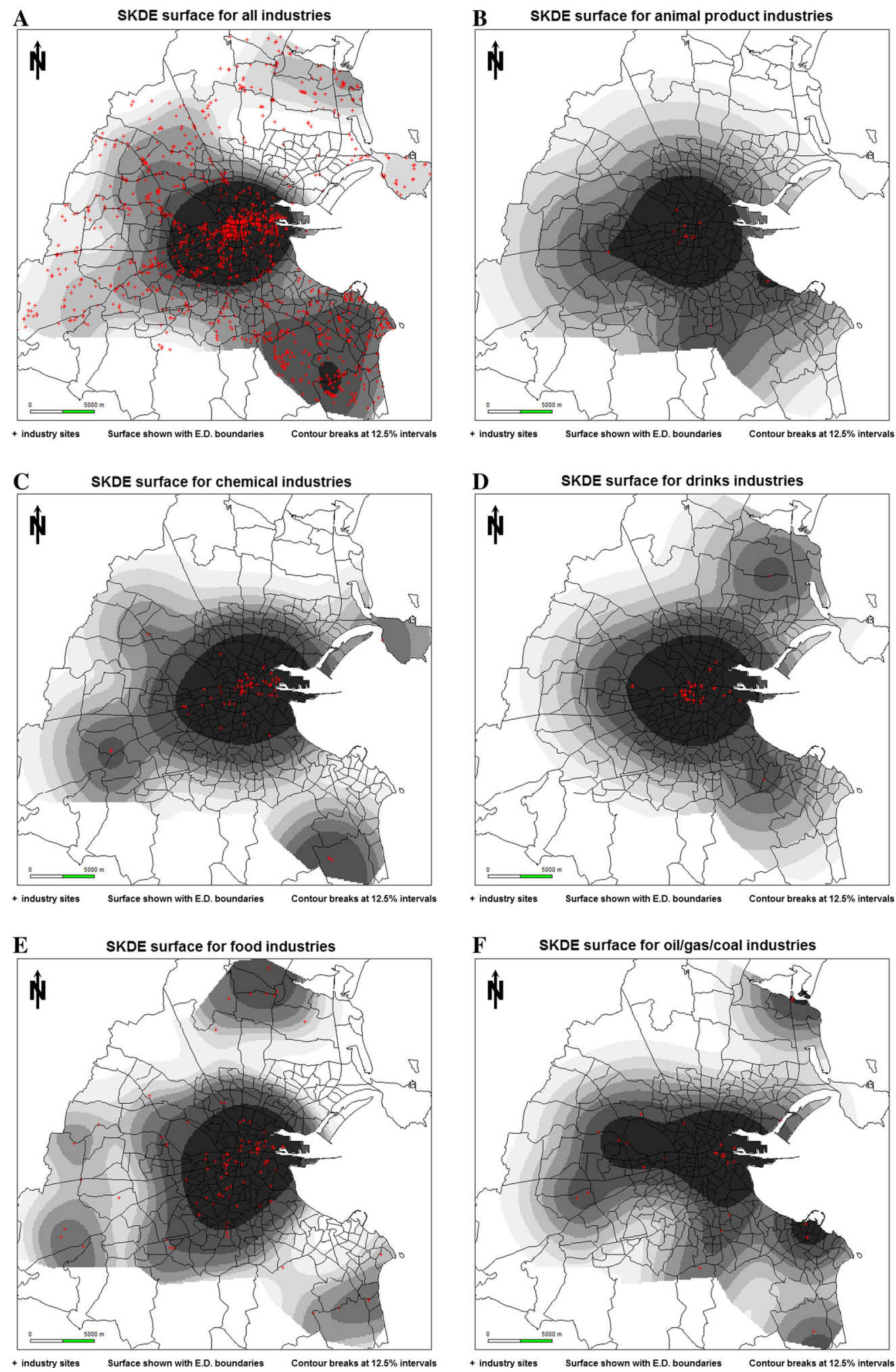

Fig. 7 Locations of historical industries with their respective SKDE surface 

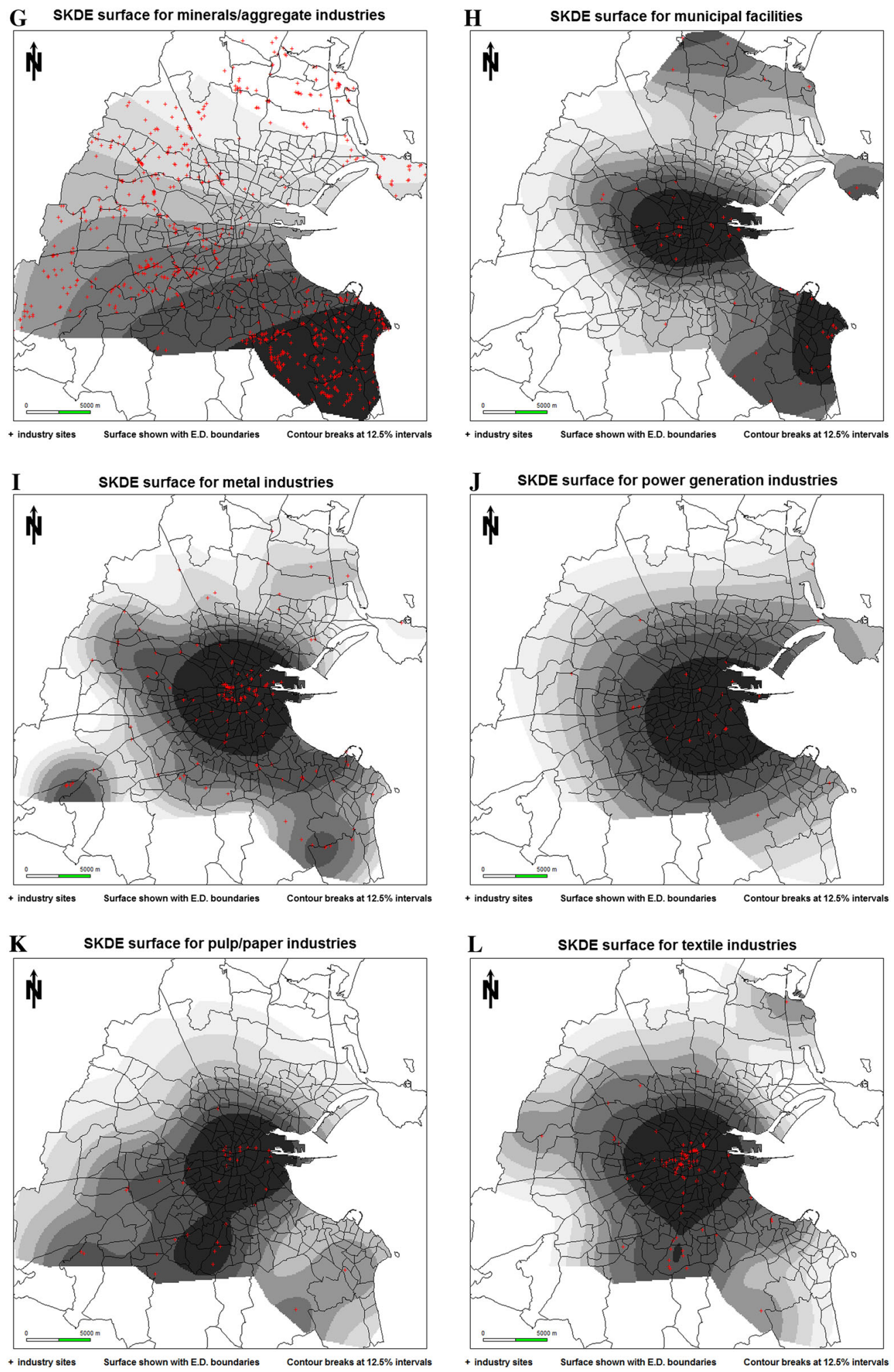

Fig. 7 continued 
bandwidths are specified by distance, not the number of nearest neighbours.

Key to this methodology is specifying the bandwidth in each of the twelve SKDEs. The smaller the bandwidth, the more rapid the spatial variation in the density estimates, while bandwidths that are too large yield results that are uninformative. In the absence of an objective approach, bandwidths were user-specified so that the correlation coefficients between the density estimates (at the geochemistry sites) and the eleven anthropogenic metals (As, $\mathrm{Be}, \mathrm{Cd}, \mathrm{Co}, \mathrm{Cr}, \mathrm{Cu}$, $\mathrm{Hg}, \mathrm{Ni}, \mathrm{Pb}, \mathrm{V}$ and $\mathrm{Zn}$ ) appeared at their strongest and positive. Table 2 presents a summary of this procedure, where for most industry categories, bandwidths of 2,000 $\mathrm{m}$ were specified.

Locations of the industries are shown in Fig. 7 , together with their gridded SKDE surfaces so that the intensity of the particular industrial activity can be visualised. Most industries tend to be centrally located in Dublin. Mineral extraction is notably focussed on an area of regional mineralisation in southeast Dublin. The textile and pulp/paper industries relied upon plentiful supplies of running water and were therefore located preferentially along the rivers Liffey, Dodder and Camac in south Co. Dublin which flow northeastwards off the Wicklow Mountains. The appearances of the SKDE surfaces are dependent on the chosen bandwidth; for example, the surface for minerals/aggregates spatially varies at a fairly large scale since it is specified with the largest bandwidth of $10,000 \mathrm{~m}$.

The correlation coefficients for the eleven anthropogenic metals and the twelve density estimates (at the study sites) were then calculated, and if required, the metals and the density estimates were transformed using a Box-Cox procedure (Box and Cox 1964). Such transformations promote the identification of linear relationships. Of the eleven metals, only $\mathrm{Cu}, \mathrm{Hg}$ and $\mathrm{Pb}$ displayed promising relationships with the density estimates (taken at correlations $>0.4$ ), and as such, only their correlations are presented in Table 3. In almost all cases, the data were transformed. Figure 8 displays a selection of associated scatterplots for those relationships that provide a correlation coefficient of 0.5 or above. All scatterplots broadly suggest that the concentrations of the given heavy metal tend to increase as the intensity of the given historical industrial activity increases. In particular, drinks, power generation and textile industries suggest an historical contamination source for soil $\mathrm{Hg}$, while drinks, oil/gas/coal, metals and power generation industries suggest an historical contamination source for soil $\mathrm{Pb}$.

Evidently, it not surprising that these particular relationships have unfolded, as high concentrations of $\mathrm{Cu}, \mathrm{Hg}$ and $\mathrm{Pb}$ tend to be located in the city centre (see Figs. 2, 3, 4), where the historical industries are similarly clustered (see Fig. 7). Thus, although many historical industry sites are likely sources of soil contamination, it is necessary to statistically evaluate the correlations demonstrated between observed soil concentrations and the historical industry. Multivariate prediction with the industry density estimates as covariates, taking into account other covariates such as land zone, other inorganic elements and organic elements, could help determine the degree to which the industry density estimates truly influence soil geochemical concentrations of $\mathrm{Cu}, \mathrm{Hg}$ and $\mathrm{Pb}$.

Table 3 Correlation coefficients for $\mathrm{Cu}, \mathrm{Hg}$ and $\mathrm{Pb}$ with the twelve historical industry SKDE variables (' $\mathrm{T}$ ' denotes transformed data)

\begin{tabular}{lllllll}
\hline & skde.all.T & skde.AP.T & skde.C.T & skde.D.T & skde.F.T & skde.OGC.T \\
\hline Cu.T & 0.37 & 0.41 & 0.45 & 0.45 & 0.45 & 0.37 \\
Hg.T & 0.38 & 0.49 & 0.44 & $\mathbf{0 . 5 1}$ & 0.44 & 0.42 \\
Pb.T & 0.45 & 0.48 & 0.47 & $\mathbf{0 . 5 3}$ & 0.46 & $\mathbf{0 . 5 0}$ \\
\hline & skde.MA.T & skde.MF.T & skde.M.T & skde.PG & skde.PP.T & skde.T.T \\
\hline Cu.T & -0.04 & 0.31 & 0.44 & 0.40 & 0.37 & 0.45 \\
Hg.T & 0.03 & 0.37 & 0.49 & $\mathbf{0 . 5 2}$ & 0.43 & 0.45 \\
Pb.T & 0.11 & 0.46 & $\mathbf{0 . 5 4}$ & $\mathbf{0 . 5 3}$ & & 0.59 \\
\hline
\end{tabular}

See Table 2 for key to industry codes

Relationships that provide a correlation coefficient of 0.5 or above are indicated in bold 

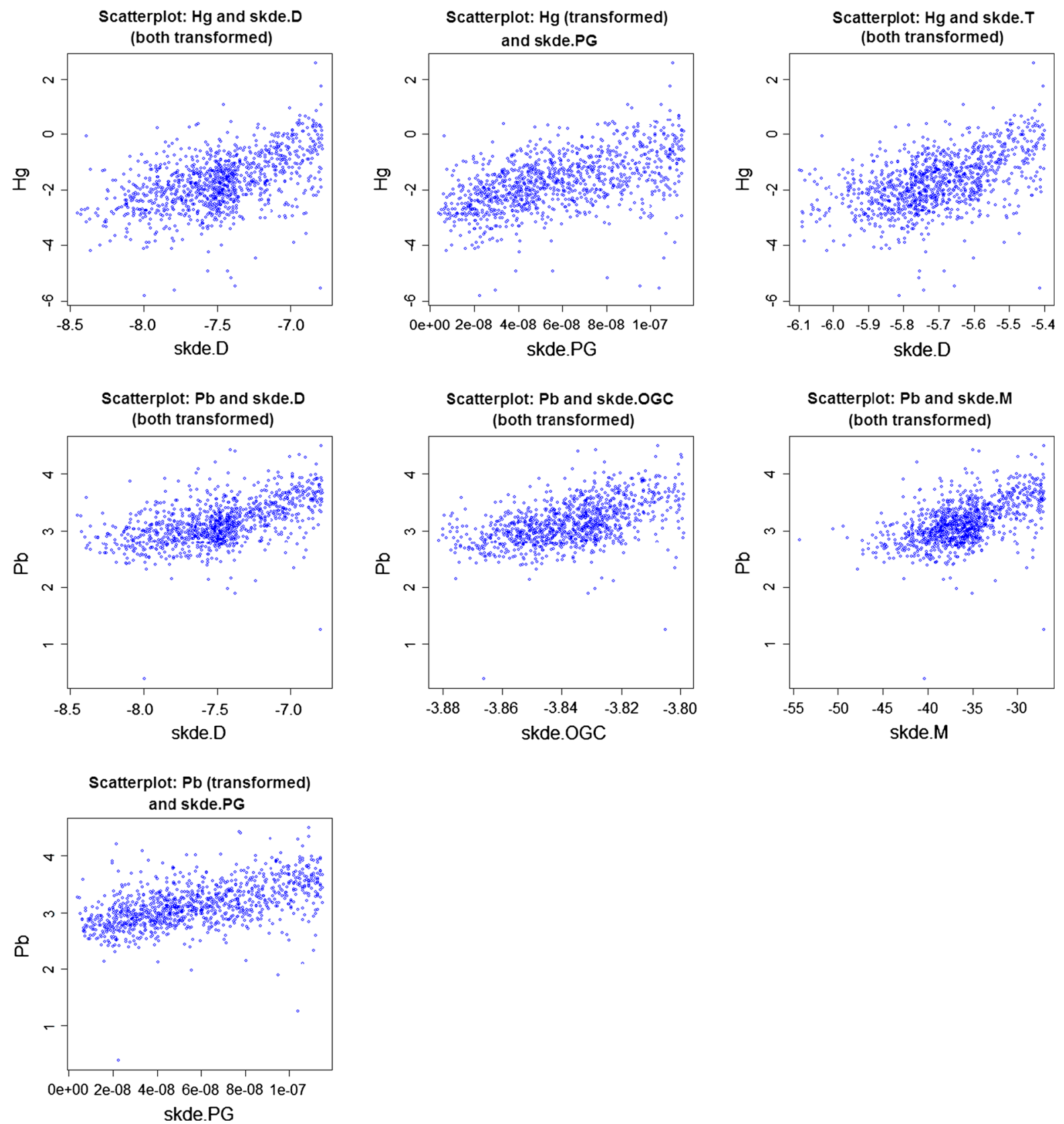

Fig. 8 Scatterplots for $\mathrm{Hg}$ and $\mathrm{Pb}$ against a selection of historical industry SKDE variables

Alternatively, replacing industry density estimates with corresponding 'distance to historical industrial site' covariates would negate the subjectivity involved in bandwidth selection when calculating the density estimates, but would not reflect the intensity of nearby industrial activity. The use of distance-based covariates can be found in the urban air pollution studies of Briggs et al. (1997) and Jarrett et al. (2005).
Comparison with other cities

Results between different studies should not be compared like-for-like unless the environmental medium (topsoil, subsoil, etc.), sampling method, sample preparation, analytical methods and detection limits are comparable (Johnson and Ander 2008). As such it is not possible to directly compare results from the 
Dublin SURGE Project with existing urban geochemical surveys carried out in other cities. However, it is informative to review results from other cities in order to put the Dublin results into a broad context.

The British Geological Survey as part of the G-Base and Tellus programmes mapped inorganic elements in topsoil in $26 \mathrm{UK}$ cities. Soil concentrations were interpreted in terms of the geological setting and industrial history of each city. A qualitative comparison of median soil concentrations in Dublin with those in a city with a history of heavy engineering (Belfast-Nice 2010), light industry (LincolnO'Donnell 2005) and heavy metal smelting (Swansea-Morley and Ferguson 2001) indicates that Dublin has moderate concentrations of heavy metals, reflecting a diverse industrial past focussed on port operations and small-scale local industry rather than large-scale heavy industry.

\section{Conclusions and further work}

Results for heavy metals indicate that the concentrations of $\mathrm{Pb}, \mathrm{Cu}, \mathrm{Zn}$ and $\mathrm{Hg}$ in topsoil are strongly influenced by human activities in Dublin. The concentrations of these metals are elevated in made ground, in the docklands, and in inner city and heavy industry areas. Sources of heavy metals in these areas include historical industry such as metal and chemical works, coal burning in homes and industry, reuse of contaminated soil and modern traffic. Concentrations of other inorganic elements in topsoil in the greater Dublin area show patterns which are strongly related to regional bedrock parent material (limestones in the Dublin basin region and the Leinster granites in southern Co. Dublin). In the case of As, multiple data populations are evident, indicating influences of natural mineralisation in the greater Dublin area and anthropogenic activity in the inner city.

The information provided by this project will assist in site-specific investigations by providing the expected concentrations in an area with regard to geological conditions and anthropogenic activity. The data set also provides a basis for the derivation of appropriate health criteria for the Irish urban environment and for the inclusion of soil geochemical concentrations as an important consideration in urban land use planning.

Studies in the UK have demonstrated that harbour sediments in industrialised cities are impacted by heavy metal pollution (Vane et al. 2011). It is recommended that a study is completed to assess the contaminant levels in aquatic sediments in the Liffey estuary and Dublin Bay. Additionally, more detailed geochemical characterisation of made ground could contribute to more effective management of contamination issues associated with made ground in public areas.

Acknowledgments Field and analytical work for this study was completed by NGU laboratories and geochemistry group staff Rolf Tore Ottesen, Malin Andersson, Ola A. Eggen, Morten Jartun, Tor Erik Finne, Audhild Hoston, Henning K.B. Jensen, Belinda Flem, Henrik Schiellerup and Bjørn WillemoesWissing. Teagasc and the National University of Ireland Galway reserve all rights of ownership and copyright in the National Soil Database data set and samples (the NSDB 2001-2005, http:// erc.epa.ie/nsdb). For Harris, the research presented in this paper was funded by a Strategic Research Cluster grant (07/SRC/ I1168) by the Science Foundation Ireland under the National Development Plan.

\section{References}

Abel, M. T., Suedel, B., Presley, S. M., Rainwater, T. R., Austin, G. P., Cox, S. B., et al. (2010). Spatial distribution of lead concentrations in urban surface soils of New Orleans, Louisiana, USA. Environmental Geochemistry and Health, 32, 379-389.

Alloway, B. J. (Ed.). (1990). Heavy metals in soils (2nd ed.). London: Blackie Academic \& Professional.

ATSDR (Agency for Toxic Substances and Disease Registry). (2007a). Toxicological profile for lead. Atlanta, GA: U.S. Department of Health and Human Services, Public Health Service.

ATSDR (Agency for Toxic Substances and Disease Registry). (2007b). Toxicological profile for arsenic. Atlanta, GA: U.S. Department of Health and Human Services, Public Health Service.

Biasioli, M., Barberis, R., \& Ajmone-Marsan, F. (2006). The influence of a large city on some soil properties and metals content. Science of the Total Environment, 356, 154-164.

Box, G. E. P., \& Cox, D. R. (1964). An analysis of transformations. Journal of the Royal Statistical Society B, 26, 211-252.

Briggs, D., Collins, S., Elliott, P., Fischer, P., Kingham, S., Lebret, E., et al. (1997). Mapping urban air pollution using GIS: A regression-based approach. International Journal of Geographical Information Science, 11, 699-718.

Bullock, P \& Gregory, P. J. (Eds). (1991). Soils in the urban environment.UK: Blackwell Scientific Publications.

Carrig Building Fabric Consultants and Mary McMahon Urban Heritage Consultancy. (2011). Dublin historic industry database. Unpublished report to the Geological Survey of Ireland. 
Chilès, J. P., \& Delfiner, P. (1999). Geostatistics-modelling spatial uncertainty. New York: Wiley.

Clancy, L. (2010). Air pollution and health in Ireland-outdoors and in pubs. In Proceedings of the society for environmental geochemistry and health conference, June 30, 2010, NUI Galway, Ireland.

CSO (Central Statistics Office). (2012). This is Ireland. Highlights from census 2011, Part 1. Dublin: The Stationery Office.

Davies, B. E. (1990). Lead. In B. J. Alloway (Ed.), Heavy metals in soils. Glasgow and London: Blackie.

DDDA (Dublin Docklands Development Authority). (2010). History-employment in the Docklands. Available online http://www.ddda.ie/index.jsp?p=629\&n=113\&a=83. Accessed 18/09/12.

Diggle, P. J. (1990). A point process modelling approach to raised incidence of a rare phenomenon in the vicinity of a pre-specified point. Journal of the Royal Statistical Society A, 53, 349-362.

EPA (Environmental Protection Agency). (2009). Air quality in Ireland 2008. Key indicators of ambient air quality. Ireland: EPA Publications Office.

Farrell, E., \& Wall, D. (1990). Soils of Dublin. Paper presented to a joint meeting of the Geotechnical Society of Ireland and the Institution of Structural Engineers, Dublin, 10 Oct 1990.

Fay, D., Kramers, G., Zhang, C., McGrath, D., \& Grennan, D. (2007). Soil geochemical atlas of Ireland. Ireland: Teagasc and the Environmental Protection Agency.

Fuge, R. (2005). Anthropogenic sources. In O. Selinus, B. J. Alloway, J. Centeno, R. B. Finkelman, R. Fuge, U. Lindh, \& P. Smedley (Eds.), Essentials of medical geology. Amsterdam: Elsevier Academic Press.

Goovaerts, P. (2009). AUTO-IK: A 2D indicator kriging program for the automated non-parametric modeling of local uncertainty in earth sciences. Computers \& Geosciences, $35,1255-1270$.

Haugland, T., Ottesen, R. T., \& Volden, T. (2008). Lead and polycyclic aromatic hydrocarbons in surface soil from day care centres in the city of Bergen, Norway. Environmental Pollution, 153, 266-272.

Heuvelink, G. B. M., \& Pebesma, E. J. (2002). Is the ordinary kriging variance a proper measure of interpolation error? In G. Hunter \& K. Lowell (Eds.), The fifth international symposium on spatial accuracy assessment in natural resources and environmental sciences (pp. 179-186). Melbourne: RMIT University.

Jarrett, M., Arain, A., Kanaroglou, P., Beckerman, B., Potoglou, D., Sahsuvaroglu, T., et al. (2005). A review and evaluation of intraurban air pollution exposure models. Journal of Exposure Analysis and Environmental Epidemiology, 15, 185-204.

Jeffries, J., \& Martin, I. (2009). Updated technical background to the CLEA model. Scientific Report SC050021/SR3. Bristol: Environment Agency.

Johnson, C. J., \& Ander, E. L. (2008). Urban geochemical mapping: How and why we do them. Environmental Geochemistry and Health, 30, 511-530.

Johnson, C. J. \& Demetriades, A. (2011). Introduction. In C. J. Johnson, A. Demetriades, J. Locutura, \& R.T. Ottesen
(Eds.), Mapping the chemical environment of urban areas. Chichester: Wiley-Blackwell.

Journel, A. G. (1986). Geostatistics: Models and tools for the earth sciences. Mathematical Geology, 18, 119-140.

McArdle, P., Williams, F. M., Doyle, E. M., Kennan, P. S., Moore-Levy, G., Gallagher, V., \& O'Connor, P. J. (1989). The metallogenic relationships of mineralisation along the southeast margin of the Leinster Granite. Geological Survey of Ireland report series. RS 86/2. Dublin: Geological Survey of Ireland.

McConnell, B. (Ed.). (1994). Geology of Kildare-Wicklow. Geology of Kildare-Wicklow. A geological description to accompany the 1:100,000 scale Bedrock Geology Map Series, Sheet 16. Dublin: Geological Survey of Ireland.

Mielke, H. W., Gonzales, C. R., Smith, M. K., \& Mielke, P. W. (1999). The urban environment and childrens health: Soils as an indicator of lead, zinc, and cadmium in New Orleans, Louisiana, USA. Environmental Research Section A, 81, 117-129.

Morley, S. E., \& Ferguson, A. J. (2001). Geochemical baseline data for the urban area of Swansea. British Geological Survey Internal report IR/01/36R.

National Archives of Ireland. (2010). Dublin: A short history. [Online] Available at www.census.nationalarchives.ie. Accessed 14/02/11.

Nice, S. (2010). Inorganic soil geochemical baseline data for the urban area of the Belfast Metropolitan Area, Northern Ireland. Geological Survey of Northern Ireland Open Report OR/08/021.

O'Connor, P. J. (2005). Human impacts. In R. Salminen (Chief Ed.), Geochemical Atlas of Europe. Part 1-Background information, methodology and maps. Espoo: Otamedia Oy.

O'Donnell, K. E. (2005). Geochemical baseline data for the urban area of Lincoln. British Geological Survey Internal Report IR/02/081.

Pardo-Igúzquiza, E., \& Chica-Olmo, M. (2005). Interpolation and mapping of probabilities for geochemical variables exhibiting spatial intermittency. Applied Geochemistry, 20, 157-168.

Pardo-Igúzquiza, E., \& Dowd, P. A. (2005a). Empirical maximum likelihood kriging: The general case. Mathematical Geology, 37, 477-492.

Pardo-Igúzquiza, E., \& Dowd, P. A. (2005b). EMLK2D: A computer program for spatial estimation using empirical maximum likelihood kriging. Computers \& Geosciences, 31(3), 361-370.

Reimann, C., Filmozer, P., Garrett, R. G., \& Dutter, R. (2008). Statistical data analysis explained. Applied environmental statistics with R. England: Wiley \& Sons Ltd.

Ribeiro, P. J., \& Diggle, P. J. (2001). GeoR: A package for geostatistical analysis. $R$ News, $1,15-18$.

Salminen, R. (Ed.). (2005). FOREGS geochemical atlas of Europe. Part 1. Background information, methodology and maps. Espoo: Geological Survey of Finland.

Schabenberger, O., \& Gotway, C. (2005). Statistical methods for spatial data analysis. London: Chapman \& Hall.

Stein, M. L. (1999). Interpolation of spatial data-some theory for kriging. New York: Springer.

UK EA (U.K. Environment Agency). (2009). Soil guideline values for inorganic arsenic in soil. Science Report SC050021/arsenic SGV. UK: Environment Agency. 
US EPA (U.S. Environmental Protection Agency). (2007). Method 3051A. Microwave assisted acid digestion of sediments, sludges, soils, and oils. USEPA.

Vane, C. H., Chenery, S. R., Harrison, I., Kim, A. W., MossHayes, V., \& Jones, D. G. (2011). Chemical signatures of the anthropocene in the Clyde estuary, UK: sediment- hosted $\mathrm{Pb},{ }^{207 / 206} \mathrm{~Pb}$, total petroleum hydrocarbon, polyaromatic hydrocarbon and polychlorinated biphenyl pollution records. Philosophical Transactions of the Royal Society A, 369(1938), 1085-1111.

Wedepohl, K. H. (Ed.). (1983). Handbook of geochemistry. Heidelberg: Springer. 